\title{
Energy innovation needs better targets
}

\author{
The renewal of Mission Innovation is important - but more targeted interventions are needed to deliver on \\ necessary energy-innovation goals.
}

$\mathrm{n}$ $\mathrm{n}$ late September, China pledged to become carbon neutral by $2060^{1}$. While details on how this will happen in practice remain to be seen, the move could prove transformative for meeting climate change targets and spurring further international agreement and progress on mitigation actions. China has played a huge role in global clean energy technology deployment over the past decade, helping drive down costs of solar panels, for example. Yet it continues to rely heavily on fossil fuels to power its own economy, even increasing its coal fleet to help with recovery from COVID-19².

China's pledge might lead to a much-needed boost for clean energy innovation. According to the International Energy Agency ${ }^{3}$, just over one-third of the cumulative emissions reductions required to meet their Sustainable Development Scenario will come from technologies that are not yet commercially available. This scenario will only reach net-zero emissions by 2070 - two decades later than the 2050 target that many are calling for. The report signals a very serious risk that we will miss our climate goals without increased support for energy research, development and deployment (RD\&D).

Meanwhile, in a Comment in this issue, Zdenka Myslikova and Kelly Sims Gallagher estimate that, after its initial five-year run, Mission Innovation (MI) has failed to achieve its key commitment to double state RD\&D investments in clean energy over the five years to 2020. Although four members did manage to double their spending, MI overall reached only an aggregate $38 \%$ increase in spending. MI was formed in 2015 alongside the Paris Agreement and comprises 24 member countries and the European Commission who have agreed to accelerate the pace of clean energy innovation. Despite falling short in their funding ambition, Myslikova and Gallagher argue that MI should still be viewed as a success, having helped to spur a surge in global activity.

MI members clearly agree: they have now agreed to a second phase for the programme ${ }^{4}$ in which they will seek to build on the past five years and expand the number of public-private alliances. More details on the second phase's commitments and targets will be announced in the next ministerial meeting in 2021.

Yet it is important to start shaping the precise nature of these objectives now. The innovation ecosystem consists of many different activities with complex feedback loops. It ranges from discovery to invention to commercialization to deployment, and back around. The timelines for each point are rarely clear - or short. It is increasingly necessary to better identify which technologies require what levels of support at which stages in the innovation lifecycle.

State support has often focused on the early research and development stages of the lifecycle and overlooked commercialization and deployment, leaving these stages for other parts of the innovation ecosystem to tend to. Yet much early-stage innovation may end up falling into the so-called valley of death without more targeted attention downstream.

This gap is illustrated in a new Analysis from Anna Goldstein and colleagues in this issue. They examined the success of 25 cleantech startups funded by the US Advanced Research Projects Agency-Energy (ARPA-E) in the programme's first year (2010) compared to other similar startups. The results indicate a strong innovation advantage for ARPA-E awardees (shown through higher patent rates) but not better business outcomes. This suggests that ARPA-E is successful in increasing innovation but that further interventions are necessary to support technology commercialization.

This is important for both MI member states and other governments that are looking to improve existing agencies or introduce new ones that aid state-driven energy innovation activities, as is happening currently in the UK, for example (https:// committees.parliament.uk/work/26

5/a-new-uk-research-funding-agency/). No single agency is likely to deliver everything that is required and the introduction of any single agency is not a silver bullet. Targeted support from agencies that have clearly defined goals and expectations is critical to enable the kind of innovation needed - and to avoid disappointment after the ribbon-cutting is over.

It's also vital that agency goals complement those of other bodies already in the innovation ecosystem. Myslikova and Gallagher call for improved and harmonized innovation policies among MI members, which should lead to more effective outcomes and set a clear direction for the private sector to respond to. Improved data collection and reporting - including on failures - will be a key aspect of developing this better policy environment and of improving the complementarity and interoperability of the ecosystem.

It has never been more important to understand what makes particular funding bodies or programmes successful ${ }^{5}$. Evidence gathering and assessment will help make better use of available resources and could increase the pace of innovation and deployment. We also need to understand more about technology deployment and consumer adoption as part of an increased focus on commercialization and deployment. This should ensure that new technologies will be commercially successful and that we are better able to develop technologies that meet both policy objectives and consumer needs. A vast literature already exists on these topics but there remains scope for further research and discussion to support government decision-making.

As challenging as delivering on energy innovation is, we should not lose sight of its important and positive impacts. Alongside the climate emergency, many nations are also having to deal with the economic ramifications of the COVID-19 pandemic. Further investment and support in clean energy innovation as part of COVID19 recovery packages will provide much needed jobs and long-term economic growth as well as help to mitigate climate change. With careful planning and the right commitments, we now have an opportunity to accelerate activity, to boost ambition, and to learn even more than before.

Published online: 15 October 2020 https://doi.org/10.1038/s41560-020-00718-0

\section{References}

1. Sengupta, S. China, in pointed message to U.S., tightens its climate targets. The New York Times https://www.nytimes.com/2020/09/22/ climate/china-emissions.html (22 September 2020).

2. Hale, T. \& Hook, L. China expands coal plant capacity to boost post-virus economy. Financial Times https://www.ft.com/content/ cdcd8a02-81b5-48f1-a4a5-60a93a6ffale (25 June 2020).

3. Energy Technology Perspectives 2020 (IEA, 2020); https://www.iea org/reports/energy-technology-perspectives-2020

4. Joint Statement from MI Members on A Second Phase (Mission Innovation, 2020); http://mission-innovation.net/wp-content/ uploads/2020/09/4.-MI-5-Joint-Member-Statement23-Sept-2020.pdf

5. Pless, J., Hepburn, C. \& Farrell, N. Nat. Energy 5, 284-290 (2020). 